\title{
Variabilidade genética em populações de Anopheles darlingi (Diptera: Culicidae) e relação ao comportamento da atividade de picar, analisada por RAPD
}

\author{
Ana Paula Barbosa da SILVA' ${ }^{\text {, Wanderli Pedro TADEI }}{ }^{2}$, Joselita Maria Mendes dos SANTOS ${ }^{3}$ \\ RESUMO \\ Duas populações naturais de Anopheles darlingi foram analisadas quanto aos padróes de variabilidade genética relacionados ao \\ comportamento hematofágico, cujas coletas foram realizadas no intra, peri e extradomicíio, em dois municípios do Estado \\ do Amazonas: Coari e Manaus. Os resultados evidenciaram amplo número de fragmentos polimórficos, bem como elevada \\ variabilidade genética nessas populaçóes. Na população de Coari, a porcentagem de locos polimórficos $(\mathrm{P})$ e heterozigosidade \\ (He) variou de $77,63 \%-84,86 \%$ e $0,2851-0,3069$, respectivamente, sendo a maior variabilidade genética detectada nas \\ subpopulaçôes do intradomicílio, e a menor nas do peridomicílio. A populaçáo de Manaus mostrou variabilidade genética \\ similar a de Coari $(\mathrm{P}=75 \%-78,94 \%$ e $\mathrm{He}=0,2732-0,2741)$, onde também foi detectada maior variabilidade genética \\ no intradomicílio. Os dados de qui-quadrado $\left(\mathrm{x}^{2}=695,89 ; \mathrm{GL}=304 ; \mathrm{P}<0,001\right)$ e de $\mathrm{F}_{\mathrm{ST}}\left(\mathrm{F}_{\mathrm{ST}}=0,0775 \pm 0,0072\right)$ foram \\ significativos, indicando uma estruturação micro geográfica, decorrente de alguma redução no fluxo gênico. Esses resultados \\ podem ser interpretados como sendo em resposta à pressão de seleção face aos inseticidas, que permanecem residuais nas \\ paredes dos domicílios.
}

PALAVRAS-CHAVE: Anopheles darlingi, malária, variabilidade genética, RAPD.

\section{Genetic variability in populations of Anopheles darlingi (Diptera: Culicidae) and relationship to biting activity behavior as analyzed by RAPD}

\begin{abstract}
Two natural populations of Anopheles darlingi, collected in the intra, peri and extra domicile of two townships in the State of Amazonas, Coari and Manaus, were assayed as to their hematophagic behaviour-related genetic variability patterns. Findings revealed a large number of polymorphic fragments as well as high genetic variability in these populations. Polymorphic loci rate $(\mathrm{P})$ and heterozygosity $(\mathrm{He})$ in the Coari population varied between $77.63 \%-84.86 \%$ and $0.2851-0.3069$, respectively, with the highest and lowest genetic variability being detected in the intra- and peri-domicile sub-populations, respectively. The Manaus population showed genetic variability and heterozygosity similar to those in Coari $(\mathrm{P}=75 \%-78.94 \%$ and $\mathrm{He}=$ $0.2732-0.2741)$, where higher genetic variability was detected in the intra-domicile as well. Chi-square data $\left(x^{2}=695.89\right.$; $\mathrm{GL}=304 ; \mathrm{P}<0.001)$ and FST $\left(\mathrm{F}_{\mathrm{ST}}=0.0775 \pm 0.0072\right)$ were significant, indicating micro-geographic structuring resulting from some decreased gene flow. These findings point out the selective pressure response to the residual insecticide remaining on household walls after the entire neighbourhood had been sprayed with it during malaria control programs.
\end{abstract}

KEYWORDS: Anopheles darlingi, malaria, genetic variability, RAPD.

1 Instituto Nacional de Pesquisas da Amazônia, INPA, CPCS - Email: anna@inpa.gov.br

2 Instituto Nacional de Pesquisas da Amazônia, INPA, CPCS - Email: tadei@inpa.gov.br

${ }^{3}$ Instituto Nacional de Pesquisas da Amazônia, INPA, CPCS - Email: jsantos@inpa.gov.br 


\section{INTRODUÇÃO}

Anopheles (Nyssorhynchus) darlingi Root, 1926 é um importante vetor de malária humana nas Américas do Sul e Central, sendo que no Brasil, ele é responsável por praticamente toda a transmissão da doença no interior do país (Deane, 1986; Rubio-Palis e Zimmerman, 1997; Tadei et al., 1998). Possui ampla distribuiçấo geográfica, estendendo-se desde o sul do México até o norte da Argentina, e das vertentes orientais da Cordilheira dos Andes até as margens do Oceano Atlântico (Forattini, 2002).

Essa espécie é considerada a mais antropofílica e endofágica dentre as dos anofelinos das Américas (Arruda et al., 1986; Tadei et al., 1988; Lourenço-de-Oliveira et al., 1989; Forattini, 2002). Vários autores destacaram a variabilidade de seu comportamento, possivelmente, resultante da ampla distribuição geográfica. A antropofilia, a exofilia, e mesmo o ritmo nictemeral têm revelado variações regionais, em maior ou em menor grau (Giglioli, 1956; Charlwood \& Hayes, 1978; Tadei et al., 1988; 1993).

Estudos realizados em diferentes localidades da Amazônia revelaram que esse mosquito apresenta um padrão de atividade de picar que se estende por toda a noite (Tadei et al., 1993). Um padrão bimodal também foi constatado, sendo um muito intenso no início da noite e outro ao amanhecer (Tadei et al., 1984). Ainda com relação a esse parâmetro, foi detectado que a atividade pode sofrer modificaçóes em sua intensidade, no início da noite, de acordo com o período de veráo e inverno (Tadei, 1993).

Outros estudos sobre o padrão da atividade de picar indicaram que $A$. darlingi costuma atacar o homem no intradomicílio, nas horas mais altas da noite. Em áreas onde as habitaçôes são borrifadas internamente com inseticidas, também pode atacar o homem, em elevada densidade, no peridomicílio, nas primeiras horas da noite. Há áreas do país, que correspondem à minoria, onde essa espécie pode ser preferencialmente exofágica. De qualquer modo, nas áreas onde ocorre, é o anofelino mais freqüente dentro do domicílio (Lourenço-de-Oliveira et al., 1989; Tadei et al., 1998).

As investigaçôes sobre a variabilidade genética em $A$. darlingi têm sido feitas usando vários marcadores moleculares, tais como: isoenzimas, RAPD, ITS2, locos microssatélites, DNA mitocondrial e a maioria deles revelaram alto grau de polimorfismo. Um estudo incorporando 15 amostras de Belize e do Brasil, usando dados de morfologia, isoenzimas, RAPD e ITS2 encontrou níveis de variabilidade genética de moderados a altos (Manguin et al., 1999). Isolamento por distância e alto grau de polimorfismo foi detectado em populaçôes procedentes da Venezuela, Brasil e Bolívia, usando dados de DNA mitocondrial (Conn et al., 1999). Elevada variabilidade genética foi encontrada em populações da Amazônia brasileira, usando dados de microssatélites (Conn et al., 2006).
Neste trabalho, estudaram-se populaçôes de Manaus e Coari, do Estado do Amazonas, com o objetivo de ampliar os dados sobre a variabilidade genética e as relaçóes com o padráo de comportamento sobre a atividade de picar de $A$. darlingi, no intra, peri e extradomicílio.

\section{MATERIAL E MÉTODOS}

\section{OBTENÇÃO DAS AMOSTRAS}

Foram analisadas populaçóes de $A$. darlingi, cujas amostras foram coletadas em 2006, nos municípios de Coari, localizado à margem direita do rio Solimóes, e de Manaus, localizado à margem esquerda do rio Negro. As capturas foram feitas a cada 60 minutos, no período compreendido entre 14:00 e 06:00h, com auxílio de um aspirador manual movido à pilha, empunhados por dois capturadores que procuram reter todos os mosquitos que se aproximam. Em Manaus, foram coletados mosquitos somente no intra e peridomicílio, enquanto que em Coari, foram coletados, também, no extradomicílio (gado).

\section{ANÁLISE MOLECULAR}

Foi extraído DNA de 30 indivíduos para cada população, seguindo-se o protocolo descrito em Wilkerson et al. (1995), com algumas modificaçóes. A reação de amplificação foi conduzida em volume total de $25 \mu \mathrm{l}$, contendo $1 \mu \mathrm{l}$ de DNA $(30 \mathrm{ng} / \mu \mathrm{l})$, 2,5 unidades de Platinum Taq DNA polimerase (Invitrogen), $2,5 \mu \mathrm{l}$ de tampão de reação $10 \mathrm{X}, 1,5 \mu \mathrm{l}$ de $\mathrm{MgCl}_{2}(50 \mathrm{mM}), 2,5$ $\mu \mathrm{l}$ de dNTP $(5 \mu \mathrm{M}), 14,7 \mu \mathrm{l}$ de água Milli-Q autoclavada e 2,5 $\mu \mathrm{l}$ de um único iniciador (Operon Technologies Inc. Alameda, CA. $/ 5 \mu \mathrm{M}$ ). A PCR foi realizada em termociclador (marca Eppendorf), programado para realizar 45 ciclos com os seguintes perfis de temperatura: 1 minuto a $94^{\circ} \mathrm{C}$, para desnaturação das fitas de DNA, 1 minuto a $36^{\circ} \mathrm{C}$, para anelamento dos iniciadores, 2 minutos a $72^{\circ} \mathrm{C}$, para alongamento das fitas sintetizadas e 7 minutos a $72^{\circ} \mathrm{C}$, para a etapa de alongamento final. Controles negativos foram incluídos. Foram utilizados dez iniciadores: AM01, AM05, AM06, AM08, AM09, AM20, OPK04, OPK07, OPK10 e OPK16.

Os produtos amplificados foram analisados em gel de agarose $(1,5 \%)$. O marcador de peso molecular utilizado foi DNA Ladder 100 pb (Invitrogen).

\section{ANÁLISE ESTATÍSTICA}

Para a análise da variabilidade genética entre as populaçóes de A. darlingi utilizou-se o Programa Tools for Population Genetics Analyses (TFPGA) na Opçáo - Marcadores Dominantes para Organismos Diplóides (Miller, 1997). Nesse caso, foi assumido cada banda como sendo um loco e que as freqüências genotípicas estavam em equilíbrio de Hardy-Weinberg. Para a estrutura genética utilizou-se o método $\Theta$ para verificar o coeficiente de endocruzamento. $\mathrm{Na}$ análise de distância e similaridade genética (Nei, 1978) e do coeficiente de diferenciação, cada parâmetro foi 
assumido como sendo uma população. Baseado nisso, utilizouse o Exact Test (Raymond e Rousset, 1995), para determinar se existem diferenças nas freqüências alélicas entre as subpopulações de Coari e de Manaus. O dendrograma, obtido a partir da matriz de distância e similaridade genética, agrupou as subpopulaçôes utilizando o método Unweighted Pairing Group Method with Arithmetic Mean (UPGMA).

\section{RESULTADOS}

A amplificação do DNA de duas populaçóes de $A$. darlingi, com um único iniciador de seqüência arbitrária, resultou numa série de fragmentos amplificados, com pesos moleculares variando de 200 a $2300 \mathrm{pb}$ (Tabela 1).

Tabela 1 - Iniciadores utilizados, número de locos e tamanho dos fragmentos obtidos no estudo populacional de Anopheles darlingi do Estado do Amazonas, usando marcadores RAPD.

\begin{tabular}{|c|c|c|}
\hline $\begin{array}{l}\text { Designação/Seqüência } \\
\text { do Iniciador }\end{array}$ & $\begin{array}{l}\text { Quantidade de } \\
\text { Locos selecionados }\end{array}$ & $\begin{array}{l}\text { Tamanho dos Fragmentos } \\
\text { (Pares de base) }\end{array}$ \\
\hline $\begin{array}{l}\text { AM01/5'- } \\
\text { CAGGCCCTTC-3' }\end{array}$ & 15 & $\begin{array}{l}400,500,700,800,900, \\
950,1050,1100,1150, \\
1500,1650,1750,2100, \\
2200 \text { e } 2300\end{array}$ \\
\hline $\begin{array}{l}\text { AM05/5'- } \\
\text { GTGACGTAGC-3' }\end{array}$ & 18 & $\begin{array}{l}400,480,520,600,700, \\
780,850,900,1000, \\
1100,1200,1300,1400, \\
1700,1900,2000,2100 \\
\text { e } 2300\end{array}$ \\
\hline $\begin{array}{l}\text { AM06/5'- } \\
\text { GGGTAACGCC-3' }\end{array}$ & 14 & $\begin{array}{l}370,430,570,600,650, \\
700,780,870,900, \\
1020,1050,1300,1700 \\
\text { e } 2000\end{array}$ \\
\hline $\begin{array}{l}\text { AM08/5'- } \\
\text { GTTGCGATCC-3' }\end{array}$ & 18 & $\begin{array}{l}400,480,520,600,650 \\
700,800,850,900,950, \\
1000,1050,1180,1300 \\
1500,1750,1900 \text { e } 2072\end{array}$ \\
\hline $\begin{array}{l}\text { AM09/5'- } \\
\text { GGACTGGAGT-3' }\end{array}$ & 14 & $\begin{array}{l}200,400,520,600,700, \\
760,800,1100,1160, \\
1200,1300,1750,2072 \\
\text { e } 2200\end{array}$ \\
\hline $\begin{array}{l}\text { AM20/5'- } \\
\text { TGCCGAGCTG-3' }\end{array}$ & 21 & $\begin{array}{l}300,400,480,520,570 \\
700,760,850,900, \\
1000,1050,1100,1200, \\
1250,1300,1400,1470 \\
1530,1750,1900 \text { e } 2100\end{array}$ \\
\hline $\begin{array}{l}\text { OPKO4/5'- } \\
\text { CCGCCCAAAC-3' }\end{array}$ & 14 & $\begin{array}{l}580,600,640,700,800, \\
920,950,1080,1170, \\
1250,1450,1520,1900 \\
\text { e } 2072\end{array}$ \\
\hline $\begin{array}{l}\text { OPK07/5'- } \\
\text { AGCGAGCAAG-3' }\end{array}$ & 12 & $\begin{array}{l}250,330,500,550,600 \\
720,850,1000,1250 \\
1420,1530 \text { e } 1850\end{array}$ \\
\hline $\begin{array}{l}\text { OPK10/5'- } \\
\text { GTGCAACGTG-3' }\end{array}$ & 13 & $\begin{array}{l}350,400,550,700,800 \\
950,1000,1100,1300, \\
1400,1600,1750 \text { e } 2072\end{array}$ \\
\hline $\begin{array}{l}\text { OPK16/5'- } \\
\text { GAGCGTCGAA-3' }\end{array}$ & 13 & $\begin{array}{l}400,480,550,620,780 \\
1000,1100,1200,1300 \\
1500,1600,2072 \text { e } 2100\end{array}$ \\
\hline
\end{tabular}

Os produtos amplificados e analisados em gel de agarose revelaram um padrão de bandas muito semelhante entre os níveis de comportamento da atividade de picar do mosquito (Figuras 1 e 2). Alguns locos foram detectados em todas as três subpopulaçóes, enquanto que outros se mostraram específicos a um indivíduo ou a uma determinada subpopulação.

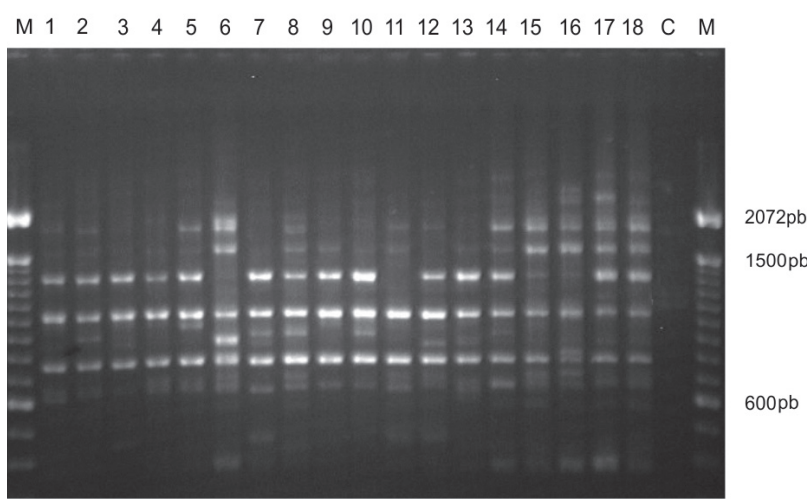

Figura 1 - Perfil da variabilidade genética em populações de Anopheles darlingi de Coari (AM), coletadas no intra, peri e extradomicílio (gado), usando o iniciador AM06. De 1 a 6 (peridomicílio), de 7 a 12 (intradomicílio), de 13 a 18 (extradomicílio); C = Controle; $\mathrm{M}=$ Marcador Molecular (Ladder 100 $\mathrm{pb}$, Invitrogen).

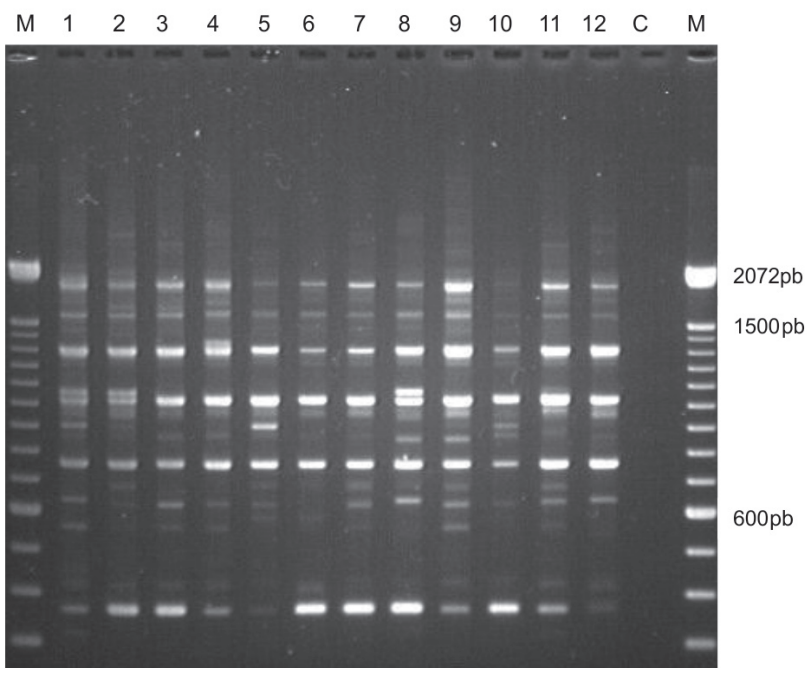

Figura 2 - Perfil da variabilidade genética em populações de Anopheles darlingi de Manaus, coletadas no intra e peridomicílio, usando o iniciador AM06. 1, 3, 5, 7, 10 e 12 (intradomicílio); 2, 4, 6, 8, 9 e 11 (peridomicílio); C= Controle; $\mathrm{M}=$ marcador molecular (Ladder $100 \mathrm{pb}$, Invitrogen).

Na populaçáo de Coari, a porcentagem de locos polimórficos e heterozigosidade média esperada variou de 77,63\% - 84,86\% e $0,2851-0,3069$, respectivamente (Tabela 2). Esses dados revelaram que, com base nos padrôes do comportamento da atividade de picar do mosquito, as subpopulaçóes do intradomicílio apresentaram maior variabilidade genética, enquanto que, a menor variabilidade foi observada no extradomicílio. $\mathrm{Na}$ população 
de Manaus, os valores de polimorfismo e heterozigosidade média esperada variaram de $75 \%-78,94 \%$ e 0,2732 - 0,2741, respectivamente (Tabela 2). Esses dados também evidenciaram que as subpopulaçôes do intradomicílio apresentaram a maior variabilidade genética. Mesmo assim, a diferença entre os valores obtidos foi baixa, revelando que essas subpopulaçôes apresentaram variabilidade genética muito similar. De qualquer forma, os resultados obtidos em Coari e Manaus, isoladamente, mostraram que as subpopulaçóes do intradomicílio apresentam maior variabilidade genética.

Os dados de qui-quadrado, a partir do Exact Test foram significativos $\left(\mathrm{x}^{2}=695,89 ; \mathrm{GL}=304 ; \mathrm{P}<0,001\right)$. $\mathrm{O}$ valor de $\mathrm{F}_{S \mathrm{ST}}$ também foi significativo $\left(\mathrm{F}_{S \mathrm{~T}}=0,0775 \pm 0,0072\right)$, e o índice de consistência do bootstrapping para 1.000 replicaçóes foi de $95 \%$, indicando uma pequena estruturação micro geográfica, decorrente de alguma barreira no fluxo gênico entre as populações. Embora algumas variaçôes genéticas tenham sido observadas entre as localidades, é possível que os acasalamentos ainda sejam aleatórios.

Tabela 2 - Estimativa da variabilidade genética nas populações de Anopheles darlingi de Coari e Manaus (AM), capturadas no intra, peri e extradomicílio, baseadas em análises RAPD.

\begin{tabular}{lcccc}
\hline População & $\begin{array}{c}\text { Número médio de } \\
\text { amostras por loco }\end{array}$ & $\begin{array}{c}\text { Porcentagem de } \\
\text { locos polimórficos * }\end{array}$ & \multicolumn{2}{c}{\begin{tabular}{c} 
Heterozigosidade média \\
\cline { 4 - 5 }
\end{tabular}} \\
\cline { 4 - 5 } Coari ID & 20 & 84,86 & 0,3012 & 0,3069 \\
\hline Coari PD & 20 & 79,60 & 0,2916 & 0,2960 \\
\hline Coari ED & 10 & 77,63 & 0,2634 & 0,2851 \\
\hline Manaus ID & 25 & 78,94 & 0,2695 & 0,2741 \\
\hline Manaus PD & 25 & 75,00 & 0,2683 & 0,2732 \\
\hline
\end{tabular}

* Freqüência do alelo mais comum, menor ou igual a 0,95;

** Estimativa não enviesada (Nei, 1978).

$\mathrm{ID}=$ intradomicílio; $\mathrm{PD}=$ peridomicílio; $\mathrm{ED}=$ extradomicílio

$\mathrm{Na}$ Tabela 3, consta a matriz de similaridade e distância genética entre as subpopulaçóes de Coari (intra, peri e extradomicílio) e Manaus (intra e peridomicílio). Com base nesses resultados, verifica-se baixa distância genética entre as subpopulaçôes analisadas. Para a populaçáo de Coari, a maior distância foi observada entre o intra e o extradomicílio $(\mathrm{D}=$ $0,0296)$ e a menor distância foi entre o peri e o intradomicílio $(\mathrm{D}=0,0081)$. Para a população de Manaus, observou-se uma baixa distância genética entre as duas subpopulaçôes $(\mathrm{D}=$ 0,0004), revelando grande similaridade entre elas.

A partir dos dados de distância genética, foi construído um dendrograma, que agrupou as subpopulaçōes em três clusters (Figura 3). O primeiro foi formado pelas amostras coletadas no intra e peridomicílio da população de Manaus. Observa-se nesse cluster que as subpopulaçôes são geneticamente muito próximas, havendo grande homogeneidade entre as mesmas. A distância genética obtida para as subpopulaçôes de Coari foram maiores do que as de Manaus. Nesse caso, elas foram agrupadas em dois
Tabela 3 - Matriz de similaridade e distância genética entre populações de Anopheles darlingi de Coari e Manaus (AM) coletadas no intra, peri e extradomicílio.

\begin{tabular}{|c|c|c|c|c|c|}
\hline População & Coari PD & Coari ID & Coari ED & Manaus ID & Manaus PD \\
\hline Coari PD & 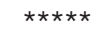 & 0,0081 & 0,0261 & 0,0297 & 0,0296 \\
\hline Coari ID & 0,9920 & 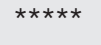 & 0,0296 & 0,0334 & 0,0337 \\
\hline Coari ED & 0,9742 & 0,9708 & 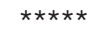 & 0,0633 & 0,0624 \\
\hline Manaus ID & 0,9707 & 0,9672 & 0,9387 & 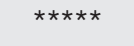 & 0,0004 \\
\hline Manaus PD & 0,9708 & 0,9668 & 0,9395 & 1,0004 & 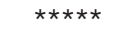 \\
\hline
\end{tabular}

Valores acima da diagonal correspondem à distância genética não enviesada e abaixo da diagonal correspondem à identidade genética não enviesada (Nei, 1978). $\mathrm{ID}=$ intradomicílio; PD = peridomicílio; ED = extradomicílio.

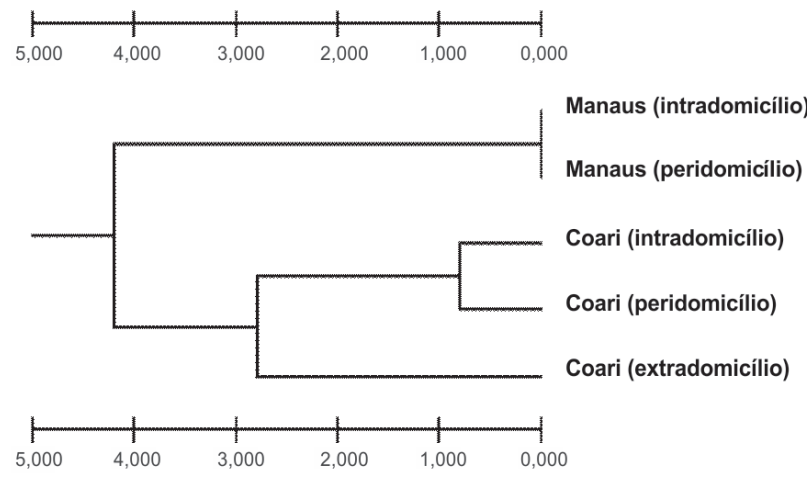

Figura 3 - Dendrograma agrupando as populações de Anopheles darlingi de Coari e Manaus, coletadas no intra, peri e extradomicílio, com base na distância genética. Método não ponderado de agrupamento de pares de populações com média aritmética - UPGMA (Nei, 1978).

clusters, sendo um deles formado pelas subpopulaçóes do intra e peridomicílio, e o outro pela subpopulação do extradomicílio.

\section{DISCUSSÃO}

A sensibilidade da técnica de RAPD na detecção de polimorfismos é grande, sendo possível a identificação de genótipos e obtenção de fingerprints. Dessa forma, os polimorfismos observados podem ser resultantes de pequenas alteraçôes na seqüência do sítio de iniciação (indels) ou de alteraçóes que modifiquem o tamanho da seqüência a ser amplificada (Williams et al., 1990). Amplo número de fragmentos polimórficos foi detectado nas populaçóes de $A$. darlingi. Para Ferreira e Grattapaglia (1995), as principais fontes de polimorfismo seriam deleçôes de sítios de iniciação ou inserçôes que colocam dois sítios de iniciação adjacentes a uma distância acima daquela que permite à DNA polimerase percorrer $(<4000 \mathrm{pb})$. Outra fonte seria a diferença em apenas um par de bases (mutação pontual), que causaria a não complementaridade 
do iniciador com o sítio de iniciação e, assim, impediria a amplificação de um segmento (Williams et al., 1990).

De acordo com Lounibos e Conn (2000), sem levar em conta o tipo de marcador (cromossomos politênicos, aloenzimas, mtDNA, RFLPs ou seqüências ITS2), todos os estudos de $A$. darlingi têm detectado níveis elevados de variabilidade genética. Alguns estudos genéticos revelaram que as populaçóes da regiấo Norte do Brasil são mais polimórficas que as do Sul, e que isso poderia estar relacionado com a heterogeneidade da floresta amazônica (Kreutzer et al., 1972; Tadei et al., 1982). Nossos resultados também indicam elevada variabilidade genética, com altos níveis de polimorfismo e heterozigosidade média, e estão de acordo com os obtidos por outros autores (Manguin et al., 1999; Santos et al., 1999; Conn et al., 2006).

Segundo Tadei et al. (1993, 1998), os níveis de exofilia e endofilia, relacionados com o hábito de picar do mosquito fora e dentro das residências, são parâmetros relevantes em estudos de populaçóes de anofelinos, pois revelam os padróes dos mecanismos de transmissão da malária. Alguns estudos realizados em populaçóes de $A$. darlingi da Venezuela, por exemplo, mostraram que a malária refratária nesse país, decorre da acentuada exofilia demonstrada pela espécie, em áreas restritas de sua distribuição geográfica (Gabaldón e Guerrero, 1959; Gabaldón et al., 1975). Este comportamento na região é apontado como causa principal da ineficiência dos inseticidas depositados no interior das residências.

Segundo levantamentos prévios, nenhum estudo tinha sido feito relacionando o comportamento da atividade de picar de A. darlingi e a variabilidade genética, os quais reunidos podem trazer informaçôes epidemiológicas valiosas sobre os níveis de exofilia e endofilia, bem como sobre possíveis adaptaçôes genéticas destes mosquitos a condiçóes de estresse.

No complexo A. gambiae da África, os estudos sobre polimorfismo cromossômico, envolvendo as duas principais espécies transmissoras da malária humana naquele continente, A. gambiae e $A$. arabiensis, mostraram que arranjos gênicos específicos estáo associados a variaçóes no comportamento, quanto à exofilia e endofilia, levando a conseqüências evolutivas e epidemiológicas relevantes (Coluzzi et al., 1979).

Na populaçáo de Coari, foi observada maior variabilidade genética nas amostras capturadas no intradomicílio, o que também foi constatado na população de Manaus. Este dado pode indicar que as subpopulaçôes do intradomicílio estáo sofrendo pressão de seleção, possivelmente decorrente de efeitos dos inseticidas residuais presentes nas paredes dos domicílios.

Segundo Tadei et al. (1993) e Akhavan et al. (1999), na região amazônica, como medida de controle do mosquito transmissor da malária, são borrifados inseticidas dentro e fora das residências. Os inseticidas borrifados fora se dispersam rapidamente, enquanto que, os de dentro permanecem por mais tempo, impregnados nas paredes dos domicílios. Uma população para explorar e se adaptar nesse ambiente alterado talvez necessite de certa plasticidade genética para obter êxito, o qual é conferida por uma alta variabilidade genética conforme discute Dobzhansky (1970).

Os dados da estrutura genética dessas subpopulaçóes revelaram valor de $\mathrm{F}_{\mathrm{ST}}$ significativo, mesmo assim, os dados de distância genética estão indicando que os acasalamentos, possivelmente, ainda sejam aleatórios. Para a população de Coari, a maior distância foi constatada entre o intra e o peridomicílio. Esse fato pode indicar que existe algum mecanismo físico, biológico ou bioquímico que esteja influenciando os dados, ou até mesmo o tamanho da amostra coletada no extradomicílio. Assim, para resultados mais conclusivos, é necessário ampliar o tamanho da amostra, bem como, analisar esses parâmetros em diferentes períodos do ano.

\section{BIBLIOGRAFIA CITADA}

Akhavan, D.; Musgrove, P.; Abrantes, A.; D’gusmao, R. 1999. Costeffective malaria control in Brazil. Cost-effectiveness of a malaria control program in the Amazon Basin of Brazil, 1988-1996. Society of Science and Medicine, 49: 1385-1399.

Arruda, M.; Carvalho, M.B.; Nussenzweig, R.S.; Maracic, M.; Ferreira, A.W.; Cochrane, A.H. 1986. Potential vectores of malaria and their different susceptibility to Plasmodium falciparum and Plasmodium vivax in northern Brazil identified by immunoassay. American Journal of Tropical Medicine and Hygiene, 35: 873-881.

Charlwood, J.D.; Hayes, J. 1978. Geographical variations in the cycle of Anopheles darlingi Root bites in Brazil. Acta Amazonica, 8: 601-603 (in Portuguese, with abstract in English).

Coluzzi, M.; Sabatini, A.; Petrarca, V.; Di-Deco, M.A. 1979. Chromosomal differentiation and adaptation to human environments in the Anopheles gambiae complex. Transactions of the Royal Society of Tropical Medicine and Hygiene, 73(5): 483-497.

Conn, J.E.; Freitas-Sibajev, M.G.R.; Luz, S.L.B.; Momen, H. 1999. Molecular population genetics of the primary malaria vector Anopheles darlingi using mtDNA. Journal of the American Mosquito Control Association, 15: 468-474.

Conn, J.E.; Vineis, J.H.; Bollback, J.P.; Onyabe, D.Y.; Wilkerson, R.C.; Póvoa, M.M. 2006. Populations structure of the malaria vector Anopheles darlingi in a malaria-endemic region of eastern Amazonian Brazil. American Journal of Tropical Medicine and Hygiene, 74(5): 798-806.

Deane, L.M. 1986. Malaria vectors in Brazil. Memórias do Instituto Oswaldo Cruz, 81: 5-14.

Dobzhansky, T.H. 1970. Genetics of the evolutionary process. Columbia University Press, New York. 451 pp. 
Ferreira, M.E.; Grattapaglia, D. 1995. Introduction to the Use of Molecular Markers in Genetic Analysis. EMBRAPACENARGEN, Brasília. 220 pp (in Portuguese).

Forattini, O.P. 2002. Medical Culicidology: identification, biology, epidemiology. Editora da Universidade de São Paulo, São Paulo. 860 pp (in Portuguese).

Gabaldón, A.; Guerrero, L. 1959. An attempt to eradicate malaria by the weekly administration of pyrimethamine in ares of out - of - doors transmission in Venezuela. American Journal of Tropical Medicine and Hygiene, 8: 433-439.

Gabaldón, A.; Garcia-Martin, G.; Sifontes, R. 1975. Necessities in the research of national program for eradication and malaria control in Venezuela. Boletin del Malaria Y Sanidad Ambiental, 15(6): 263-285 (in Spanish)Giglioli, G. 1956. Biological variations in Anopheles darlingi and Anopheles gambiae: their effect on practical malaria control in the neotropical region. Bulletin World Health Organization, 15: 461-471.

Kreutzer, R.D.; Kitzmiller, J.B.; Ferreira, E. 1972. Inversion polymorphism in the salivary gland chromosomes of Anopheles darlingi Root. Mosquito News, 32: 355-365.

Lounibos, L.; Conn, J.E. 2000. Malaria vector heterogeniety in South America. American Entomology, 46: 238-249.

Lourenço-de-Oliveira, R.; Guimarães, A.E.; Arlé, M.; Silva, T.F.; Castro, M.G.; Motta, M.A.; Deane, L.M. 1989. Anopheline species, some of their habitats and relation to malaria in endemic areas of Rondonia State, Amazon region of Brazil. Memórias do Instituto Oswaldo Cruz, 84: 501-514.

Manguin, S.; Wilkerson, R.C.; Conn, J.E.; Rubio-Palis, Y.; DanoffBurg, J.A.; Roberts, D.R. 1999. Population structure of the primary malaria vector in South America, Anopheles darlingi, using isozyme, ITS2, RAPD and morphological markers. American Journal of Tropical Medicine and Hygiene, 60: 364-376.

Miller, M.P. 1997. Tools for population genetic analyses (TFPGA): $A$ Windows program for the analysis of allozyme and molecular population genetic data, version 1.3. Northern Arizona University, Arizona.

Nei, M. 1978. Estimation of average heterozigosity and genetic distance from a small number of individuals. Genetics, 89: 583-590.

Raymond, M.; Rousset, F. 1995. Genepop (version 1.2): population genetics software for exact test and ecumenicism. Journal of Hereditary, 86: 248-249.

Rubio-Palis, Y.; Zimmerman, R.H. 1997. Ecoregional classification of malaria vectors in the neotropics. Journal of Medicine and Entomology, 34: 499-510.
Santos, J.M.M.; Lobo, J.A. Tadei, W.P; Contel, E.P.B.1999. Intrapopulational Genetic Differentiation in Anopheles (N.) darlingi Root, 1926 (Diptera: Culicidae) in the Amazon Region. Genetics and Molecular Biology, 22: 231-325.

Tadei, W.P. 1993. Biology of Amazonian Anophelines. XVIII. Considerations about Anopheles species (Culicidae), transmission and malaria control in the Amazon region. Revista da Universidade do Amazonas, 2(1-2): 1-34 (in Portuguese, with abstract in English).

Tadei, W.P.; Santos, J.M.M.; Rabanni, M.B., 1982. Biology of Amazonian Anophelines. V. Chromosomal polymorphism of Anopheles darlingi Root (Diptera: Culicidae). Acta Amazonica, 12: 353-369 (in Portuguese, with abstract in English).

Tadei, W.P.; Santos, J.M.M.; Cunha, S.A. 1984. About chromosomal polymorphism of Anopheles darlingi Root (Diptera: Culicidae). Ciência e Cultura, 36(7): 916-920 (in Portuguese, with abstract in English).

Tadei, W.P.; Santos, J.M.M.; Costa, W.L.S.; Scarpassa, V.M. 1988. Biology of Amazonian Anophelines. XVII. Occurrence of Anopheles species, dynamics of transmission and malaria control in urban area of Ariquemes (Rondônia). Revista do Instituto de Medicina Tropical de São Paulo, 30: 221-251 (in Portuguese, with abstract in English).

Tadei, W.P.; Santos, J.M.M.; Scarpassa, V.M.; Rodrigues, I.B. 1993. Incidence, distribution and ecological aspects of Anopheles species (Diptera: Culicidae) in natural and environmental impact areas of Brazilian Amazon, p. 167-196. In: Ferreira, E.J.G.; Santos, G.M.; Leão, E.L.M.; Oliveira, L.A. (Eds.). Scientific Bases for Development and Preservation Strategies of the Amazon. Vol. 2. Instituto Nacional de Pesquisas da Amazônia, Manaus, Amazonas (in Portuguese).

Tadei, W.P.; Thatcher, B.D.; Santos, J.M.M.; Scarpassa, V. M.; Rodrigues, I.B.; Rafael, M.S. 1998. Ecologic observations on anopheline vectors of malaria in the Brazilian Amazon. American journal of tropical medicine and hygiene, 59: 325-335.

Wilkerson, R.C.; Parson, T.J.; Klein, T.A.; Gaffgan, T.V.; Bergo, E.; Consolim, J. 1995. Diagnosis by random amplified polymorphic DNA polymerase chain reaction of four cryptic species related to Anopheles (Nyssorhynchus) albitarsis (Diptera: Culicidae) from Paraguay, Argentina and Brazil. Journal of Medicine and Entomology, 32(5): 697-704.

Williams, J.G.K.; Kubelik, A.R.; Livak, K.J.; Tingy, S.V. 1990. DNA polymerase amplified by arbitrary primers are used as genetic markers. Nucleic Acids Research, 18(22): 6531-6535.

Recebido em 21/02/2008

Aceito em 27/05/2009 